\title{
OLHARES E REFLEXÕES SOBRE O CORPO NA CULTURA CONTEMPORÂNEA
}

\author{
M. S. FILHO ${ }^{1}$; H. A. GALVÃO DE SOUZA ${ }^{2}$ \\ ${ }^{1}$ IFRN. Doutor em Educação pela UFRN. E-mail: moyses.filho@ifrn.edu.br \\ ${ }^{2}$ UERN. Doutora em Educação pela UERN. E-mail: hunaway@bol.com.br
}

Artigo submetido em Março/2015 e aceito em Setembro/2015

\section{RESUMO}

O presente artigo discute a questão do corpo na atualidade, com uma breve representação do corpo na contemporaneidade, na perspectiva dos fundamentos da antropologia social e da fenomenologia educacional, analisando o descolamento do corpo do próprio ser humano. Discute a emergência e a construção do sujeito numa abordagem crítica sobre o anatomismo corporal. Desse modo, do tergiversado corpo máquina ao corpo virtual, perdemo-nos do que seria a verdadeira essência do ser humano: o corpo em sua natureza e na dimensão cultural do movimento. Reforça-se a discussão, a partir do olhar adolescente dos educandos do 2 o ano do ensino médio integrado do curso de informática do IFRN - campus Natal Zona Norte, como princípio pedagógico do conteúdo Ginástica, através das falas resultantes de uma avaliação diagnóstico aplicada aos educandos e educandas.. Na discussão abordada pelo escrito, buscamos compreender como o corpo tem sido visto e tratado como objeto pelo sistema político econômico e científico. A superação desse paradigma limitante, por meio de ações educacionais da Educação Física no ensino médio integrado contextualizadas com os princípios do projeto político institucional, pode contribuir para uma ruptura significativa dos interesses externos à existência plena da

PALAVRAS-CHAVE: Corpo; ser humano; cultura; movimento.

\section{LOOKS AND THOUGHTS ON THE BODY IN CONTEMPORARY CULTURE}

\begin{abstract}
This article discusses the issue of body today with a brief representation of the body in contemporary society from the perspective of the foundations of social anthropology and educational phenomenology, by analyzing how it occurs the body detachment of the human being itself. Discusses the emergence and construction of the subject in a critical approach on body anatomy. Thus misrepresented the machine body to the virtual body, lost in what would be the very essence of the human being, the body in nature and cultural dimension of movement. Reinforcing the argument from the look of teenage students of the 2nd year of the integrated high school's computer class of IFRN - campus natal north zone, as a
\end{abstract}

pedagogical principle content gymnastics through the speeches of the students resulting from a diagnostic evaluation. On the discussion addressed by writing, we seek to understand how the body has been seen and treated as objects by the economic and scientific political system and how we can contribute pedagogically to overcome this limiting paradigm through educational actions of physical education in the integrated high school curriculum that are contextualized with the principles and concepts of institutional political project, seeking to contribute to a significant disruption of determinism and outside interests to the essence and full of corporeal existence.

KEYWORDS: body; human being; culture; movement. 
O PULSO

O pulso ainda pulsa

O pulso ainda pulsa...

E o corpo ainda é pouco

Assim...

Reumatismo, raquitismo

Cistite, disritmia

Hérnia, pediculose

Tétano, hipocrisia

Catapora, culpa, cárie

Cãibra, lepra, afasia...

O pulso ainda pulsa

E o corpo ainda é pouco

Ainda pulsa

Ainda é pouco

Assim...

TITÃS

\section{UMA BREVE REPRESENTAÇÃO CONTEMPORÂNEA DO CORPO}

Vigorexia, cosmetologia, suplementação alimentar, regime da moda, emagrecimento, fortalecimento muscular, anorexia, bulimia, chás milagrosos são algumas das palavras que fazem parte do léxico contextual das promessas em busca da perfeição do corpo perfeito na atualidade. São muitas as palavras que nos lembram a letra da música do Titãs, Pulso, citada no início desse escrito. Podemos ver, na mídia, vários indícios desse crescente e permanente interesse pelo que se relaciona com o corpo, mas sempre focados nos interesses do ideário mercadológico.

Ao mesmo tempo em que são divulgados os benefícios para o corpo, uma grande parcela da sociedade não adere às fórmulas mágicas e continua a conviver com seu corpo mediante as exigências e condições cotidianas da vida doméstica, do trabalho, do estudo, das emoções, enfim, de todas as dimensões humanas que fazem parte da vida das pessoas. Nesse sentido, a questão que se apresenta para uma abordagem metodológica no processo de ensino e de aprendizagem em nossa prática pedagógica encontra respaldo no pensamento acerca da problemática da corporeidade no mundo.

Refletindo sobre a existência - sobre o nosso próprio destino, sobre o homem em sua humanidade, sobre os acontecimentos culturais e sociopolíticos do mundo em geral e da realidade brasileira, e sobre o sentido da educação -, buscamos atingir uma maior compreensão do real, que nos sirva de apoio e orientação para a nossa práxis cotidiana (GONÇALVES, 2008, p. 9).

De acordo com Silva (2001, p. 14), "no Brasil, a disseminação de corpo baseada na estética da magreza é bastante grande e apresenta uma enorme repercussão, especialmente se considerada do ponto de vista da realização pessoal". Como podemos perceber, mesmo mais de uma década depois, essas e outras questões relativas ao corpo ainda permeiam o imaginário social na busca do corpo perfeito, tais como as cirurgias plásticas, as dietas variadas, os tipos de ginástica para que o corpo seja moldado à imagem e semelhança do perfeccionismo da forma física.

Um dos problemas dessas obsessões particulares é a banalização das questões sociais que ampliam a identidade do corpo no âmbito cultural e na sua relação com a natureza. Segundo Silva (2001), a Arte também foi muito influenciada pelo movimento científico que se estruturou fortemente a partir do século XVII, através das obras que caracterizam uma nova expectativa em relação aos corpos humanos e 
cita, como exemplo, a Lição de Anatomia do Doutor Tulp, pintada por Rembrandt em 1632. Outros campos da expressão e do conhecimento humano abordaram e conceituaram o corpo numa perspectiva acurada e inédita até então.

Na modernidade, o corpo passou a receber um tratamento contraditório que apresenta uma intenção de dominá-lo e ao mesmo tempo libertá-lo; subjugá-lo e depender dele para ser feliz; acreditar na superioridade e independência da mente e, ao mesmo tempo, se submeter aos rituais necessários para manter o corpo em forma (SILVA, 2001). No entanto, será que aparentamos ser o que realmente somos? É como se só pudéssemos ver o corpo de fora, por fora e para fora de si. Constrói-se um escudo no corpo pelo próprio corpo. Assim sendo, "faz-se necessária uma reflexão acerca dos discursos, práticas e valores atribuídos a essa "onda no corpo", evitando assim uma possível, e já visível, banalização do corpo e do movimento humano" (NÓBREGA 2005, p. 18).

Compreendemos, pois, que é preciso superar a visão do corpo como um objeto moldado pela tecnociência, descolado da sua realidade e procurar resgatar os princípios das relações entre o homem, o corpo, a natureza e a cultura, ou seja, o homem enquanto um ser total, dotado de razão e sensibilidade; o corpo como a síntese das dimensões humanas; a natureza em todos os seus aspectos relacionais com a teia da vida e a cultura como expressão da criatividade e dos valores artísticos de um povo.

Nessa perspectiva, o corpo põe-se em relação com o mundo e deixa de ser um produto mecânico submetido e subjugado aos ditames da produção de conhecimento das diversas áreas de pesquisa, seus usos e aplicações relacionadas aos aspectos históricos, sociais, políticos, econômicos e culturais da existência humana. Desse modo, haveria uma correspondência contextual entre os propósitos existenciais que implicam nas condições de vida plena da corporeidade.

\section{A EMERGÊNCIA DO INDIVÍDUO E A CONSTRUÇÃO DO SUJEITO}

As partes do corpo estão no mercado. Para qualquer parte que alguém queira substituir ou remodelar, existem ofertas de produtos e serviços reparadores. Essa condição para uma pseudossaúde estética pode acarretar problemas físicos irreversíveis ou mesmo vir a causar óbitos, como de vez em quando é noticiado. Essa razão instrumental produz uma síndrome frankensteiniana coletiva e causa no imaginário social pensamentos, intenções, desejos e decisões sobre que corpo tenho e sobre que corpo quero ter.

\footnotetext{
Com isto nos aproximamos cada vez mais das supostas promessas do saber médico. Um saber que pretende decifrar esta máquina da forma mais apropriada. Nosso apego às possíveis descobertas acerca do corpo se fortificam diariamente. Parece-nos que cabe ao cenário contemporâneo, mais precisamente à medicina, engrandecida de conhecimento e tecnologia, atender as nossas necessidades, anseios e mais íntimos desejos. Descobrir o funcionamento e o provável domínio sobre os fenômenos do corpo, sobretudo, da vida e da morte se revelam como ícones do viver moderno. Percebemos que a objetividade no conhecimento é condição para a eficácia na ação, mas ação num sentido muito específico, que é o de produção ou fabricação. Falamos de um corpo que pode ser modificado a partir das intervenções da ciência presentificadas nas ações médicas (DANTAS, 2011 p. 899).
}

Nesse mundo de intervenções técnicas da medicina com suporte tecnológico cada vez mais em evolução, o corpo se encontra numa trincheira vivencial sem poder ser visto e concebido tal qual ele é em toda a sua inteireza. "Numa civilização como a atual, completamente dominada pela chamada racionalidade instrumental, o corpo/mente dos indivíduos tende a se tornar um "outro", estranho para seus próprios donos" (LEFEVRE e LEFEVRE, 2009 p. 67). 
Os campos da antropologia, da sociologia e da psicologia têm desenvolvido estudos e pesquisas sobre o corpo na sociedade e no plano da subjetividade humana. Busca-se, na discussão desses estudos, um indivíduo consciente de si em todos os sentidos sociais e culturais assim como na perspectiva significativa da construção do sujeito político.

\begin{abstract}
$\mathrm{Na}$ cultura da atualidade, marcada por valores dominantes como competição, consumismo, o corpo é um corpo pautado no individualismo, "contido pela musculatura", é um "corpo mercadoria", um "corpo-aparência", um "corpo-ferramenta", um "corpo-consumidor", um corpo com função de promoção social, que pode trazer um retorno, um corpo que deve expressar saúde, saúde que se torna século XXI (VASCONCELOS et al., 2004, p.76).
\end{abstract}

Mas o que é a saúde? É apenas um estado de ausência de doenças? Ou seria algo bem mais amplo que se inicia nas relações sociais, políticas e econômicas com implicações e repercussões nos corpos das pessoas? Sem a intenção de nos aprofundarmos no tema da saúde e na sua complexidade como dimensão essencial da vida, optamos por entender que não podemos abordar a questão da saúde na sociedade apenas pelo aspecto do funcionamento fisiológico e curativo.

A amplitude da saúde social vai muito além dos programas de governo que não atendem ao paradigma holístico de saúde. É necessário contemplar o ser humano, as condições materiais da qualidade de vida e a proteção ambiental para sermos sucintos nos aspectos imediatos para uma saúde social. Paralelo ao que não é feito em prol da saúde social, "uma nova cultura de consumo se estabelece a partir da imagem do corpo bonito, sexualmente disponível e associado ao hedonismo, ao lazer e à exibição, enfatizando a importância da aparência e do visual" (NÓBREGA, 2010 p. 23). De acordo com a autora, todos os apelos midiáticos transformam o corpo em um outdoor tanto no plano visual quanto no plano sensitivo do próprio corpo. As pessoas vestem-se, portam-se e comportam-se para que sejam vistas e admiradas pelo que a aparência imagética do corpo expressa.

Onde está o sujeito contextualizado? Onde está o indivíduo e a sua identidade política e cultural? Onde está o ser humano integrado aos complexos do corpo, da natureza e da cultura? Essas respostas ainda precisam ser amplamente discutidas de modo que possamos superar os limites ideológicos de como o corpo deve se moldar aos determinismos sociais, políticos e econômicos hegemônicos na sociedade contemporânea.

Para Sant'Anna (1995, p. 12):

Torna-se fundamental localizar as problematizações que tornam possível uma série de práticas e de representações corporais. Desse modo, não se trata de realizar uma listagem das maneiras supostamente exóticas de lidar com o corpo em outras épocas, mas sim de tornar questionáveis os gestos e as atitudes que ontem e hoje nos parecem familiares ou não. Pois o corpo é, ele próprio, um processo.

Ressaltando a visão da autora, o corpo representa a convergência entre as técnicas expressivas e a cultura da sociedade, expõe seus sentimentos e objetos de interesse além de contextualizar a sua própria história. Não pertence a uma trajetória linear, mas antes e de forma permanente e simbiótica, apoia-se nos saberes construídos a partir dele como fonte inesgotável de conhecimento.

Todos os saberes que permeiam o corpo nascem da originalidade antropológica do ser humano e são ampliados por outros saberes sistematizados pelas técnicas e suportes políticos, sociais e tecnológicos associados. Portanto, é no corpo e pelo corpo que nascem todas as dimensões dos saberes humanos. No entanto, a utilização dos conhecimentos pelas ciências ocorre para o domínio e exploração do corpo e não para a sua libertação. Não temos o direito de separar o corpo dele mesmo nem de tratá-lo às expensas de si. 
Como pensa Nóbrega (2010, p. 117), “a animação do corpo não está no inventário das partes ou na encarnação de um espírito como polos opostos; encontra-se na experiência do corpo, em sua reflexividade capaz de colocar o sujeito em relação com o mundo e assim inaugurar atos de conhecimento". Assim sendo, a simbiose homeostática do corpo em conexão com o meio em que está inserido, proporcionará uma realidade de vida intensa ao desenvolver, no mesmo, possibilidades de desencadear atitudes em equilíbrio dinâmico e intencional ante a complexidade da vida.

\title{
3 ALGUNS OLHARES ADOLESCENTES SOBRE O CORPO
}

Qual concepção de corpo será concebida e vivida pela geração de adolescentes da atualidade? Como eles se percebem como corpos em vida? O que é vida ou sobrevida do corpo? Para Lefevre e Lefevre (2009),

A adolescência é caracterizada por um período de mudanças. Fisicamente é caracterizada pelo crescimento corporal, pela explosão hormonal e paralelamente, por diversas transformações psicossociais. Por isso, sua vulnerabilidade e seu risco são afetados por transformações internas e externas.

Com essa compreensão, desenvolvemos uma avaliação diagnóstica sobre a concepção de corpo na atualidade, tendo como suporte metodológico a concepção das aulas abertas em Educação Física (HIDEBRANDT, LAGGING 1986) ${ }^{1}$, a partir da visão dos educandos e educandas do curso técnico integrado de nível médio, da turma do 20 ano do curso de informática do IFRN - campus Natal Zona Norte. Como processo metodológico de ensino para o conteúdo Ginástica, do componente curricular Educação Física, partimos de uma questão acerca do que os educandos e educandas pensam sobre o tema: 'o corpo na atualidade como fonte de consumo, de prazer e de contestação da ordem social'.

Os sujeitos que responderam à questão, são jovens de várias classes sociais, com interesses sócio culturais e pessoais diversificados e estão na faixa etária entre 16 e 17 anos. Iremos apresentar a seguir, na íntegra, a transcrição de algumas opiniões dos educandos e das educandas da turma em foco, que foram redigidas pelos próprios sujeitos e que, no nosso entendimento pedagógico, contextualizam-se com essa discussão por representar o olhar adolescente sobre as perspectivas presentes do corpo. Perspectivas essas, que nos permitem vislumbrar boas possibilidades de confirmação do pensamento em transformação dos sujeitos em foco acerca da temática da relação do corpo com o conceito de Ginástica como conteúdo presente no percurso pedagógico do currículo da Educação Física com as temáticas e vivências com as práticas corporais.

\section{A educanda I considera que:}

\begin{abstract}
"Atualmente, mídia, tecnologia e ciência as propagam com outros objetivos. O estilo de vida moderna parece influenciar doenças cardiovasculares, obesidade, depressão e estresse. Novamente a atividade física é um remédio. Mas a mídia (não somente ela) desconstrói esse pensar sobre o corpo à medida que o torna objeto de consumo e manipulação do próprio ser humano, que parece não ter história. Os meios de
\end{abstract}

\footnotetext{
${ }^{1}$ A Abordagem da Concepção de Aulas Abertas está fundamentada na vida de movimento das crianças, na história de vida e na construção da biografia esportiva dos estudantes de E.F., na concepção de esporte e movimento que a sociedade vem construindo ao longo da história e na realidade das aulas de Educação Física Escolar. A concepção de Aulas Abertas em Educação Física considera a possibilidade de co-decisão no planejamento, objetivos, conteúdos e formas de transmissão e comunicação no ensino. HILDEBRANDT, R.; LAGING, R. Concepções abertas ao ensino da educação física. Rio de Janeiro: Livro Técnico, 1986.
} 
comunicação de massa constroem e apresentam à sociedade o corpo desejável, "perfeito", transformado e "feliz": protótipo de beleza. Nesse aspecto, a beleza do corpo padrão se detém exclusivamente na aparência: vestir-se de acordo com a moda, exercitar-se três horas por dia, alimentar-se à base de produtos diet e light, transformarse a partir de recursos biotecnológicos. Tudo isso em nome da "saúde" e de beleza! Vivese entre a imagem real e a imagem ideal! As imagens em capas de revistas, outdoors, embalagens de cosméticos etc. são pessoas esbeltas e olhos brilhantes, corpos quase despidos, vestidos com roupas de ginástica ou biquínis".

A educanda J, compreende que:

"Ao longo da humanidade padrões foram criados para determinar o feio e o belo, da Grécia antiga até então a preocupação em ter um corpo bonito, um corpo no caso dentro dos padrões sempre esteve presente na cabeça e nas ambições das pessoas. Hoje, mais do que qualquer período da história o corpo se tornou um grande mercado que mobiliza milhões anualmente, academias, salões de beleza, cosméticos, suplementos e etc. movimentam esse mercado cada vez mais".

Para a educanda $\mathrm{V}$,

"Como sabemos, é evidente que na atualidade, os corpos, cada vez mais, ganham visibilidade e são tratados como mercadorias a serem vendidos pela indústria de saúde. A publicidade dá a impressão de que um corpo perfeito, apresentado como significado de saúde, bem-estar e felicidade está ao alcance de todos desde que sejam seguidas determinadas prescrições. Assim o corpo é tratado com rascunho que pode ser modelado e remodelado ao gosto do seu dono. Isso causa vários problemas acerca dos distúrbios de autoimagem como, anorexia, bulimia e vigorexia, na busca pelo corpo idealizado do consumo. Infelizmente, esta situação é o que a atualidade transmite para mim pois hoje em dia o bem-estar passou a ser "mal-estar" onde o prazer se associa ao esforço, o sucesso ao controle e a perfeição ao sofrimento".

O educando $\mathrm{M}$, acredita que:

“Hoje em dia, é inevitável não pensar no modo como o corpo é valorizado e como isto vem se tornando o modo de vida da sociedade atual. O culto ao suposto corpo perfeito se mostra como característica principal da época em que vivemos e é baseado na busca diária por um corpo ideal que supere qualquer expectativa e problema imposto a ele. $\mathrm{O}$ corpo se tornou um grande objeto de investimento para os principais meios de comunicação atuais, como aquilo que pode ser manipulado ou modificado. A importância dada ao corpo na sociedade é tanta, que muitos vivem para isso e em consequência, esquecem outras coisas mais necessárias".

O Educando A, entende que:

"Bem, nos dias atuais o corpo é visto apenas como um troféu, algo que se almeja, um corpo "ideal" na sociedade atual é tido como aquele malhado, sarado...e quanto aos demais são vistos com desprezo pela maioria das pessoas, ter esse "corpo perfeito" causa uma sensação de prazer, bem-estar, se bem que a utilização do corpo para o prazer vai bem além, já que muitas pessoas mesmo tendo ou não esse modelo de corpo já sente e usa-o para o prazer não só dele, mas de outros também. Se bem que hoje esse tipo de "corpo" gera uma grande discussão social, muitas pessoas concordam, outras discordam, já que você não precisa ter esse "corpo perfeito" para ser feliz. Felicidade vai muito além do físico, ela está mais ligada ao emocional de cada um". 
Essa pequena amostra de opiniões dos educandos e das educandas secundaristas representa um tipo de pensamento que circula entre os jovens vistos como outsiders corporais e, aqui, abrimos um parêntesis para esclarecer essa perspectiva, haja vista que esses jovens não se encontram dentro e nem em acordo com o sistema ou com o plano do atual paradigma de corpo contemporâneo que vem sendo exposto pela sociedade midiática que estabelece padrões ideais de aceitação pela aparência visual. Apesar de serem jovens e de terem cada um seu tipo e consciência da beleza juvenil, não se deixam levar pelos padrões dos estereótipos corporais vigentes.

De certo modo, acreditamos que o processo educacional desenvolvido pelo componente curricular Educação Física no campus Natal Zona Norte a partir das séries iniciais dos cursos integrados profissionalizantes tem contribuído para que esses educandos e educandas possam construir uma visão crítica que permita a aceitação de si e a adoção de práticas corporais que sejam e estejam contextualizadas com os seus processos de realização pessoal, social, emocional e existencial. Para tal, o referido processo educacional além de considerar educandos e educandas como sujeitos em formação, que têm experiências precedentes e diversificadas com a Educação Física escolar; ainda prioriza ações pedagógicas dialógicas e lúdicas que possam ter significado e fazer sentido para o processo de formação integral dos sujeitos,

Desse modo, acreditamos que o processo de ensino e de aprendizagem possa estar contextualizado com uma prática pedagógica da Educação Física em consonância com os princípios do projeto político pedagógico institucional - PPP/IFRN ${ }^{2}$ e com as abordagens metodológicas da proposta de trabalho pedagógico da Educação Física no ensino médio integrado profissionalizante.

\section{PENSAR O CORPO: UMA ATRIBUIÇÃO CURRICULAR DA EDUCAÇÃO FÍSICA}

Ao analisarmos o descompasso entre a função social da escola e as práticas pedagógicas curriculares que ainda são comuns no campo da Educação Física escolar, cada vez mais nos convencemos que é preciso superar os limites políticos e culturais presentes no currículo do nível médio para o componente curricular. Apesar dos avanços nos estudos e proposições do currículo para a Educação Física no ensino médio como por exemplo, as propostas oficiais contidas nos PCN's + (2000) e nas orientações curriculares para o ensino médio - OCEM (2006), as esferas oficiais e privadas de ensino, por exemplo, não têm definidos objetivos comuns quanto às políticas educacionais e suas implicações sociais para a Educação Física nesse nível de ensino.

De acordo com Moreira (2010, p. 19),

Se por um lado identificamos os problemas do ensino médio, no que diz respeito a sua coerência interna, por outro, devemos lembrar que o aluno do ensino médio está em uma fase da vida de grandes transformações, decisões e de muitas incertezas, fato esse agravado pela diversidade sociocultural e socioeconômica desses jovens. A escola tem que estar atenta a isso, se a preocupação maior é o ato educativo.

\footnotetext{
${ }^{2}$ O Projeto Político-Pedagógico do IFRN vem se consolidando desde 1994, com a elaboração da Proposta Curricular da ETFRN. À medida que o processo foi sendo consolidado e sistematizado, todos os documentos e as contribuições decorrentes dos grupos de trabalho dos campi foram depositados ampliando, dessa forma, os espaços de discussões e de construção coletiva. O Projeto político pedagógico adotado hoje pelo IFRN é resultado de uma construção coletiva. Disponível em: http://www2.ifrn.edu.br/ppi/doku.php.
} 
Ao atentarmos para essa condição cultural, defendemos que o processo de ensino e de aprendizagem dos conteúdos da Educação Física deve estar focado nas necessidades dos sujeitos e na sua formação crítica em relação aos determinantes históricos, políticos e sociais, haja vista que, segundo Neira e Nunes (2009), "ganham destaque tanto as estreitas conexões entre a característica construída do currículo e a produção de identidades sociais e culturais quanto a descrição das diversas formas de conhecimento corporificadas no currículo".

A abordagem pedagógica do conteúdo Ginástica a partir da visão dos educandos sobre a condição do corpo na sociedade atual, buscou estabelecer uma compreensão da corporeidade como um complexo de sensibilidades que não se limitam aos movimentos esportivos tradicionais relacionados ao tema. Optamos, no componente curricular, a partir de uma reflexão conjunta, estabelecer um percurso pedagógico de vivencias das práticas corporais que se integrem à elaboração do conhecimento em Educação Física de modo que este possa ser construído socialmente. Pressupomos que a partir do exposto, esses sujeitos possam refletir sobre as suas existencialidades de modo que não se deixem levar pelo determinismo alienante que paira na atmosfera comunicativa sobre o que tem sido considerado como corpo perfeito, ideal ou qualquer palavra que isole o corpo de si e da sua realidade imediata e original.

Noutra perspectiva, o componente curricular Educação Física, cumpre a função social e política de, a partir de uma proposta pedagógica contextualizada com os princípios da concepção de ser humano, sociedade, cultura, ciência, tecnologia, trabalho e educação contida no PPP institucional com práticas pedagógicas, questionar os limites dos currículos prontos. Essas práticas pedagógicas devem, portanto, ter significado e fazer sentido no processo de formação educacional dos sujeitos do ensino médio.

\section{REFERÊNCIAS}

1. DANTAS, Jurema. Um ensaio sobre o culto ao corpo na modernidade. Estudos e pesquisa em psicologia (on line). Rio de Janeiro; V.11; №. 3. p.898-212. 2011.

2. GONÇALVES, Maria Augusta Salin. Sentir, pensar, agir. Corporeidade e educação. Campinas, SP. Papirus, 11a edição; 2008.

3. HILDEBRANDT, R.; LAGING, R. Concepções abertas ao ensino da educação física. Rio de Janeiro: Livro Técnico, 1986.

4. LEFEVRE, Fernando; LEFEVRE, Ana Maria Cavalcante. $\mathbf{O}$ corpo e seus senhores: homem, mercado e ciência: sujeitos em disputa pela posse do corpo e da mente humana. Rio de Janeiro. Vieira \& Lent, 2009.

5. MOREIRA, Wagner Wey. Aulas de Educação Física no ensino médio. Campinas, SP. Papirus, 2010.

6. NEIRA, Marcos Garcia; NUNES, Mario Luiz Ferrari. Educação Física, currículo e cultura. São Paulo, SP. 2009.

7. NÓBREGA, Terezinha Petrucia da. Corporeidade e educação física: do corpo-objeto ao corposujeito. 2a ed. Natal: EDUFRN, 2005.

8. Uma fenomenologia do corpo. São Paulo. Editora Livraria da Física, 2010.

9. SANT'ANNA, Denise Bernuzzi de. Políticas do corpo. São Paulo: Estação Liberdade, 1995.

10. SILVA, Ana Márcia. O corpo do mundo: algumas reflexões acerca da expectativa de corpo atual. In a [des]construção do corpo. José Carlos Granado (organizador). Blumenau: Edifrurb, 2001.

11. VASCONCELOS, Naumi A. de; SUDO, lana; SUDO, Nara. Um peso na alma: o corpo gordo e a mídia. Rev. Mal-Estar e Subj., Fortaleza, v.4, n.1, mar. 2004. Disponível em $<$ http://pepsic.bvsalud.org/scielo.php?script=sci_arttext\&pid=S151861482004000100004\&lng=pt \&nrm=iso>. Acesso: 14 mar. 2015. 